Jakob Julius Nolte

\title{
Die Eigenart des verwaltungsgerichtlichen Rechtsschutzes
}

Grund und Grenzen der Anwendung des Zivilprozessrechts im Verwaltungsprozess

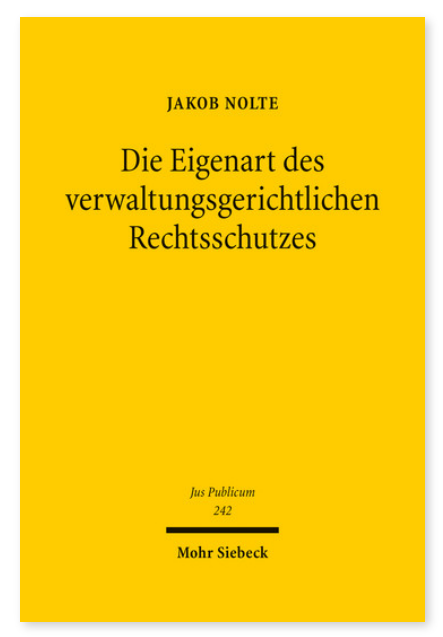

2015. XX, 678 Seiten. JusPubl 242

ISBN 978-3-16-152838-5

DOI 10.1628/978-3-16-152838-5

eBook PDF 159,00€

ISBN 978-3-16-152837-8

Leinen $159,00 €$
Bis heute gibt es keine vollständige Prozessordnung für den Verwaltungsprozess. Die VwGO verweist dort, wo sie keine eigenen Regelungen enthält, auf das Zivilprozessrecht. Die Übernahme des Zivilprozessrechts stößt aber an ihre Grenzen, wenn die Regelungen sich nicht mit den Funktionen des verwaltungsgerichtlichen Verfahrens vertragen. Dies wird von den Gerichten von Fall zu Fall entschieden, ohne dass dabei eine klare Linie erkennbar wäre. Jakob Nolte widmet sich den rechtlichen Grundlagen und den Grenzen für die Übertragung des Zivilprozessrechts auf das verwaltungsgerichtliche Verfahren. Dabei geht es um eine dogmatisch einwandfreie Systematisierung der selektiven Übernahme des Zivilprozessrechts. Der Autor zieht eine klare Linie zwischen den Funktionen und den Grundsätzen des verwaltungsgerichtlichen Verfahrens und der Lösung der Anwendungsprobleme im Einzelfall. Hierbei achtet er insbesondere auf eine klare Dogmatik bei der Anwendung des differenzierten Verweisungssystems der VwGO.

Jakob Julius Nolte Geboren 1974; Studium der Rechtswissenschaften in Konstanz und Madrid; Stipendiat der VW-Stiftung; Wissenschaftlicher Mitarbeiter an der Humboldt-Universität zu Berlin; Referendariat am Kammergericht Berlin; 2004 Promotion; 2012 Habilitation; seit 2012 Lehrstuhlvertreter an der HU Berlin.

Jetzt bestellen:

https://mohrsiebeck.com/buch/die-eigenart-des-verwaltungsgerichtlichen-rechtsschutzes-9783161528385?no_cache=1 order@mohrsiebeck.com

Telefon: +49 (0)7071-923-17

Telefax: +49 (0)7071-51104 